\title{
Esophageal lumen recreated with a self-expanding metal stent in a deep submucosal tunnel: a successful way to treat a refractory stricture
}

Esophageal strictures can be refractory to endoscopic dilations, making the goal of achieving oral feeding challenging. Self-expandable metal stents (SEMS) have been disappointing, with low success rates [1-3]. For complete esophageal obstruction, recanalization by endoscopic submucosal dissection (ESD) has been described, bridging between the upper and the lower edges of the stricture beneath the mucosa [4]. Previous experience of ESD for recurrent lesions has taught us that a residual nonfibrotic submucosal layer can be present close to the muscle [5].

We here present the case of a 72-year-old man with a refractory esophageal peptic stricture, who underwent 14 unsuccessful dilations over 3 years and then developed a diverticulum above the stricture ( $\triangleright$ Video 1). First, we decided to attempt a kind of Zenker's peroral endoscopic myotomy to cure the fibrotic ring that had given rise to the diverticulum, but once we started to make the submucosal tunnel, we found that the deep submucosa was not fibrotic. Thus, we continued the deep submucosal tunnel to below the stricture area and retrieved the esophageal lumen by cutting through the mucosa from the tunnel into the esophagus. We decided to introduce a SEMS into the tunnel to form a new esophageal lumen (๖Fig.1). Three months later, after removal of the stent, esophageal opacification showed the esophageal lumen to be regular and wide, without any stricture ( $>$ Fig. 2). A small ring of fibrosis was still present on one side of the esophagus, and this was cut to prevent food impaction. Following stent removal, the patient noticed improvement of the dysphagia, and the improvement persisted 1 month later, with weight gain. However, endoscopic dilations were still necessary to maintain this good clinical result.

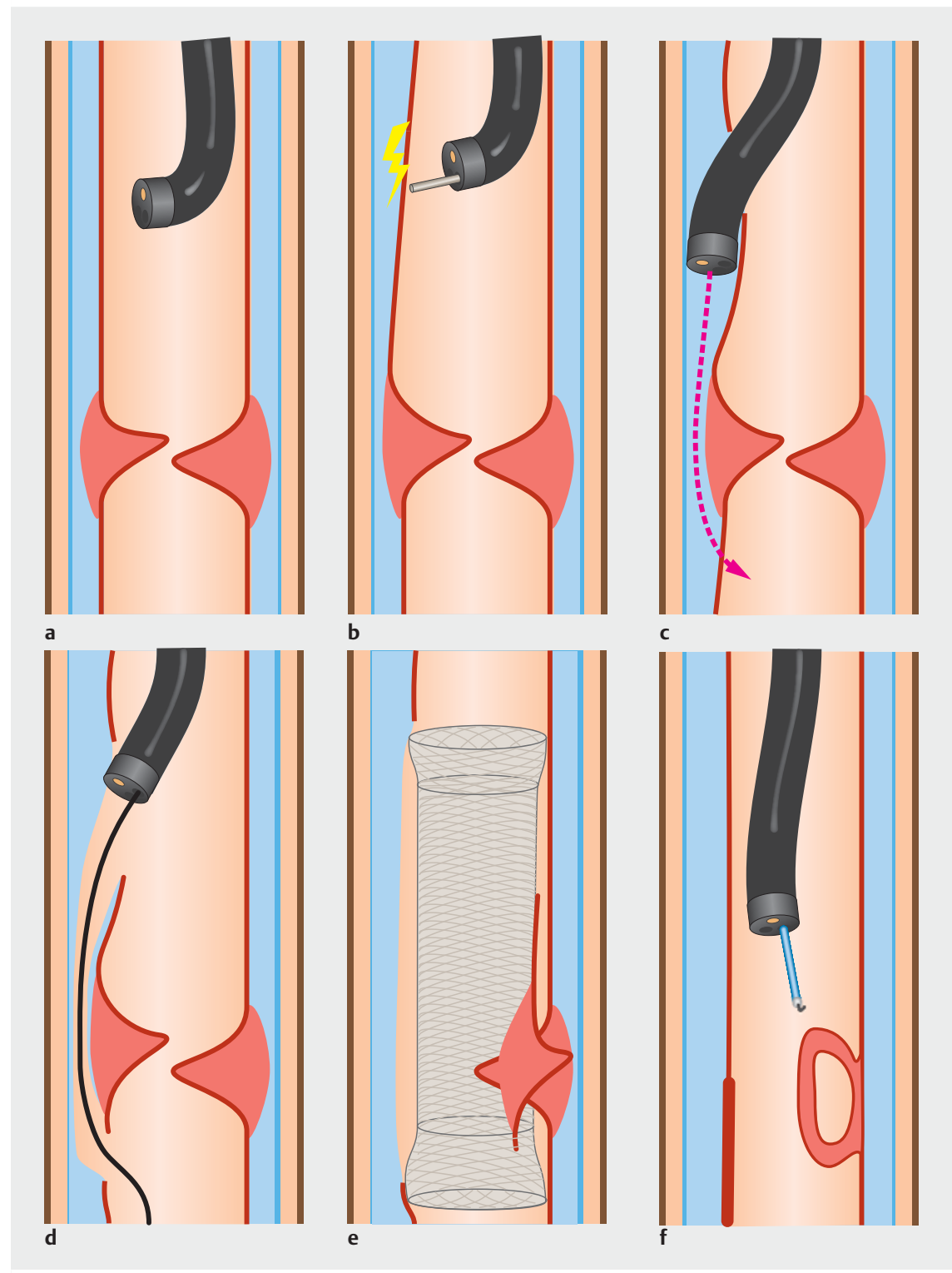

- Fig. 1 Schematic illustration of the procedure. a, b A submucosal tunnel was created from a point above to a point below the stricture. $\mathbf{c}$ The esophageal lumen was retrieved by cutting through the mucosa from the tunnel into the esophagus. d, e A self-expanding metal stent (SEMS) was placed in the tunnel. $\mathbf{f} A$ residual small ring of fibrosis was cut to prevent food impaction.

To summarize, in patients with refractory esophageal stricture, using the deep submucosal layer to place a stent into a tunnel could allow the creation of a new esophageal lumen without stricture. Al- though attractive, this technique needs further evaluation in larger population studies.

Endoscopy_UCTN_Code_TTT_1AO_2AN 


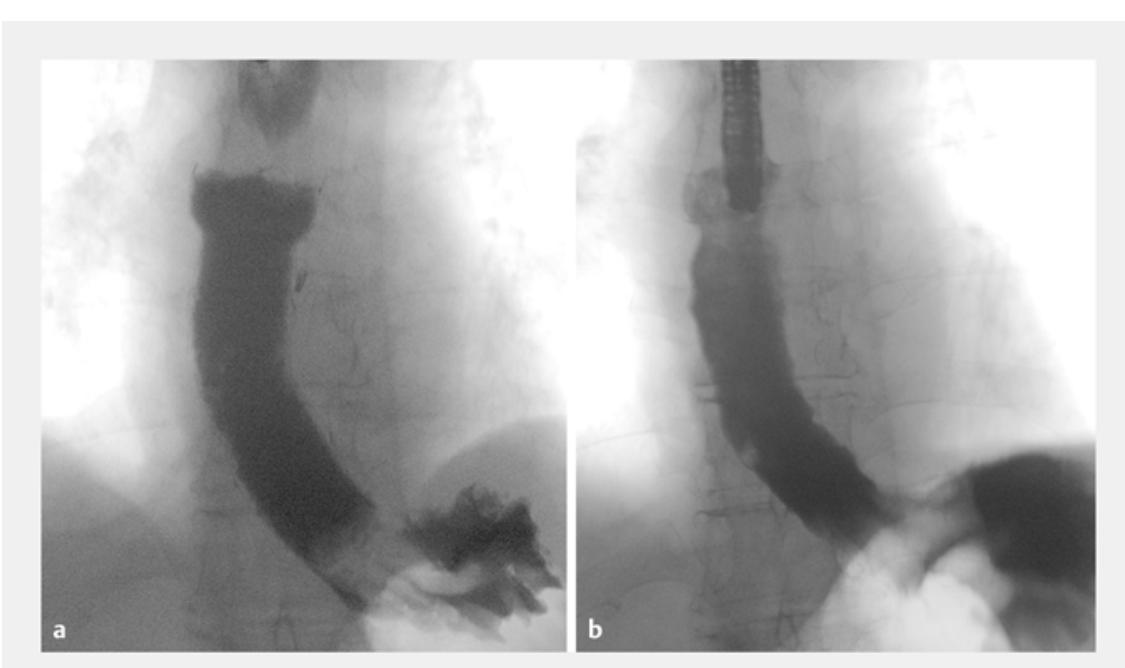

- Fig. 2 Esophageal lumen after opacification: a before SEMS removal, b after SEMS removal.

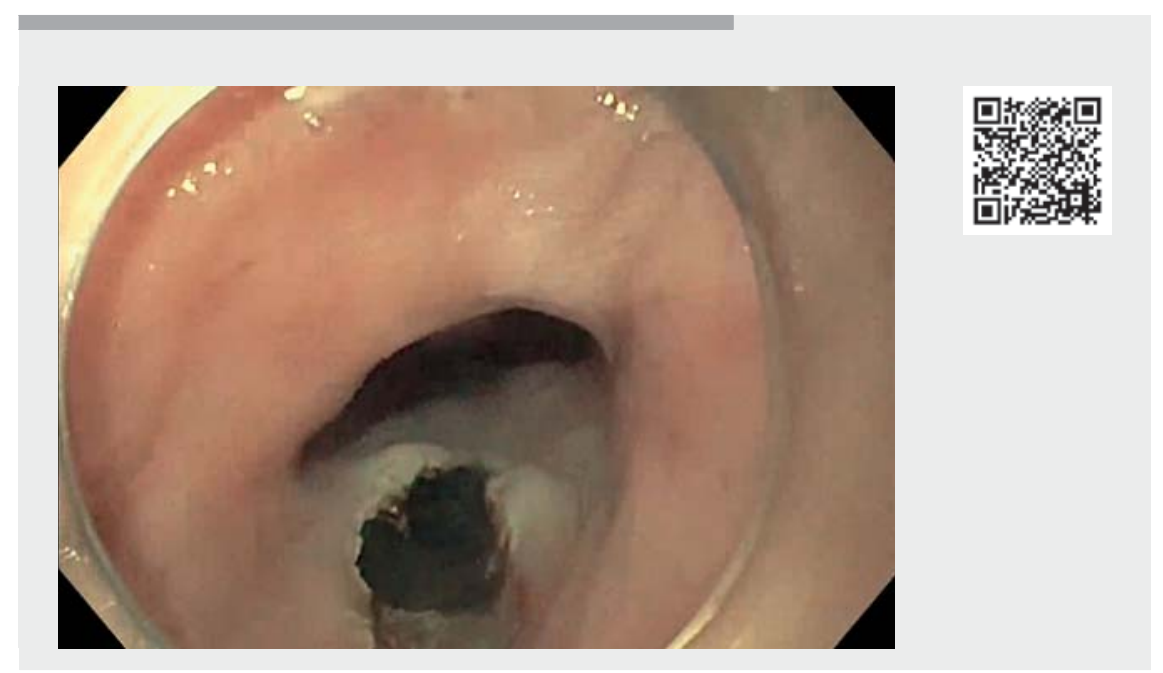

$\checkmark$ Video 1 Esophageal lumen recreated with a self-expanding metal stent in a deep submucosal tunnel: a successful way to treat a refractory stricture.

\section{Competing interests}

The authors declare that they have no conflict of interest.

\section{The authors}

\section{Caroline Dellestable ${ }^{1}$, Thomas Lambin ${ }^{1,2}$,} Jérôme Rivory ${ }^{1}$, Jean-Christophe Saurin', Jérémie Jacques ${ }^{3}$, Thierry Ponchon ${ }^{1}$, Mathieu Pioche $^{1,2}$

1 Gastroenterology and Endoscopy Unit, Pavillon L, Edouard Herriot Hospital, Lyon, France

\section{References}

[1] van Boeckel PGA, Vleggaar FP, Siersema PD. A comparison of temporary self-expanding plastic and biodegradable stents for refractory benign esophageal strictures. Clin Gastroenterol Hepatol Off Clin Pract J Am Gastroenterol Assoc 2011; 9: 653-659

[2] Gangloff A, Lecleire S, Di Fiore A et al. Fully versus partially covered self-expandable metal stents in benign esophageal strictures. Dis Esophagus Off J Int Soc Dis Esophagus 2015; 28: 678-683

[3] Fuccio L, Hassan C, Frazzoni L et al. Clinical outcomes following stent placement in refractory benign esophageal stricture: a systematic review and meta-analysis. Endoscopy 2016; 48: 141-148

[4] Mavrogenis G, Moreels TG, Chevaux J-B et al. Recanalization of a complete postradiation esophageal obstruction with endoscopic submucosal dissection techniques. Gastrointest Endosc 2015; 81: 1476

[5] Faller ], Jacques ], Oung B et al. Endoscopic submucosal dissection with double clip and rubber band traction for residual or locally recurrent colonic lesions after previous endoscopic mucosal resection. Endoscopy 2020; 52: 383-388

Bibliography

Endoscopy 2022; 54: E139-E140

DOI $10.1055 / \mathrm{a}-1418-7727$

ISSN 0013-726X

published online 16.4 .2021

(c) 2021. Thieme. All rights reserved.

Georg Thieme Verlag KG, Rüdigerstraße 14, 70469 Stuttgart, Germany

\section{ENDOSCOPY E-VIDEOS \\ https://eref.thieme.de/e-videos}

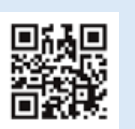

Endoscopy E-Videos is an open access online section, reporting on interesting cases and new techniques in gastroenterological endoscopy. All papers include a high quality video and all contributions are freely accessible online. Processing charges apply (currently EUR 375), discounts and wavers acc. to HINARI are available.

Endoscopy Unit, Digestive Diseases Department, Pavillon L - Edouard Herriot Hospital, 69437 Lyon Cedex, France thomaslambin@hotmail.fr
This section has its own submission website at https://mc.manuscriptcentral.com/e-videos 